\title{
Research Square \\ Explicit dynamics based numerical simulation approach for assessment of impact of relief hole on blast induced deformation pattern in an underground face blast
}

\section{VIVEK HIMANSHU ( $\sim$ vivekbit07@gmail.com )}

Central Institute of Mining and Fuel Research CSIR https://orcid.org/0000-0002-7583-8508

\section{A K Mishra}

Indian School of Mines: Indian Institute of Technology

\section{Ashish K Vishwakarma}

Central Institute of Mining and Fuel Research CSIR

M P Roy

Central Institute of Mining and Fuel Research CSIR

P K Singh

Central Institute of Mining and Fuel Research CSIR

\section{Research Article}

Keywords: Blast induced deformation, Relief hole, Overbreak, Numerical Simulation, Isosurface, Waveform Analysis

Posted Date: June 11th, 2021

DOl: https://doi.org/10.21203/rs.3.rs-549827/v1

License: (c) (i) This work is licensed under a Creative Commons Attribution 4.0 International License. Read Full License

Version of Record: A version of this preprint was published at Geomechanics and Geophysics for GeoEnergy and Geo-Resources on December 7th, 2021. See the published version at https://doi.org/10.1007/s40948-021-00327-5. 


\title{
Explicit dynamics based numerical simulation approach for assessment of impact of relief hole on blast induced deformation pattern in an underground face blast
}

\author{
Vivek K Himanshu $^{1 *}$, A K Mishra ${ }^{2}$, Ashish K Vishwakarma ${ }^{1}$, M P Roy $^{1}$, \& P K Singh ${ }^{1}$
}

1. CSIR-Central Institute of Mining and Fuel Research (CSIR-CIMFR), Barwa Road, Dhanbad-826015

2. Indian Institute of Technology (Indian School of Mines), Dhanbad

*vivekbit07@gmail.com

\begin{abstract}
The breakage of rock mass by blasting has many challenges. The optimal breakage in an underground development face/tunnel blast is dominantly dependent on the relief area provided to the blast holes. The cut portion in the burn cut face blast is significantly important to achieve the controlled deformation due to the blast. This paper has discussed the impact of the number and diameter of the relief holes on the breakage pattern of the rock. The numerical simulation with varying numbers and diameter of relief hole was carried out for this purpose. Finite element modeller explicit dynamics of Ansys-Autodyn was used for the simulation work. The isosurface of non-deformed zone was plotted to compare the extent of deformation under varying conditions of relief holes. The analysis shows that the higher number of relief holes with optimum diameter gives more controlled deformation than single relief hole with larger diameter. The nearfield vibration was also recorded by placement of seismograph. The waveform analysis of the recorded vibration was carried out. The redesigning of the blasting pattern was done using the results of numerical simulation and waveform analysis. The redesigned pattern consists of four relief holes of $115 \mathrm{~mm}$ diameter. The blasting output with the revised design has resulted into the considerable improvements in the pull and reduction of overbreak. The revised pattern has addressed the issue of the socket formation at the site.
\end{abstract}

Keywords: Blast induced deformation; Relief hole; Overbreak; Numerical Simulation; Isosurface; Waveform Analysis

\section{Article Highlights}

* The manuscript covers numerical simulation based approach for assessment of blast induced deformation in an underground face blast under different variations of diameter and numbers of relief holes.

* The numerical simulation based output reveals that the blast face shows more controlled deformation while using multiple number of relief holes of optimum diameter as compared to a single large relief hole.

* The numerical simulation output in this paper has been used to redesign the blasting pattern of the face blast of a Lead-Zinc underground mine. 


\subsection{Introduction}

Excavation in tunnel or drives of an underground metal mine is dominantly performed by drilling and blasting technique. The controlled blasting technique is practiced to optimise the blast induced deformation. The higher extent of deformation in rock strata is termed as overbreak. This overbreak leads to the irregular profile of the tunnel. On the other hand, blast designers also pose the problems of under breakage along the direction of excavation. This results in to the pull reduction and socket formation. The optimal rock breakage aims to maximize the pull and minimize the overbreak from the blast. The optimisation needs site specific investigations relating the geotechnical parameters of the rock mass. Bieniawski (1968) suggested that the study of fracture propagation characteristic of rock can lead to improve the efficiency of rock breaking using drilling and blasting. The excavation in drivages of underground metalliferous mine dominantly follows the Burn-Cut pattern. This pattern has a set of cut holes containing empty (relief) as well as blast holes. Since the tunnel/drive excavation has free face along the single direction as compared to two free faces in case of bench blasting, the optimum explosive energy utilisation in the face blast requires additional free face (Gupta et al. 1988; Adhikari 1994; Murthy \& Dey 2002; Verma et al. 2018). This additional free face is provided by drilling the relief holes, which are kept uncharged during the process of blasting. Accordingly, the dimension of relief holes including its diameter, depth and the area of relief plays significant role in achieving the optimum rock breakage due to blasting (Singh 1995). However, the optimum relief hole dimension for a blast face is a function of rock mass properties, explosive properties, presence of geological discontinuities etc. Accordingly, the assessment of breakage pattern in a burn cut face blast with respective rock and explosive combinations will provide an idea for the optimum relief hole dimension. Sharma (2005) studied the impact of multiple relief holes on the breakage pattern of a face blast. Author found that the multiple relief holes in place of a single large diameter relief hole are more relevant in order to prevent freezing in the spongy rock mass (Sharma 2005; Allen 2014).

The blast induced deformation pattern in the burn cut face blasting has foremost impact of rock mass properties. The literature suggests that the rock breakage under explosive loading follows physical phenomenon such asporous compaction, compressive cracking, tensile breakage etc. (Ding et al. 2013). These physical phenomena are represented by various rock mass properties such as - uniaxial dynamic compressive strength, uniaxial dynamic tensile strength, elastic modulus, poison's ratio etc. Verma et al. (2016) found that the ultrasonic wave velocities are also important parameter influencing the strata requirement for detonation velocity of explosive. The development blast faces of the underground metalliferous mines are also under the influence of insitu stresses. 
These insitu stresses also have impact on the damage pattern of a face blast. Researchers have explained that the pre-stressed strata are prone to show higher magnitude of overbreak under similar explosive loading condition (Mandal \& Singh 2009; Abdel-Meguid et al. 2003; Xiao et al 2019). Mandal \& Singh (2009) emphasized to do excavations in small sections and phases in order to minimize overbreak and reduce peripheral damages under highly stressed strata conditions. The geological discontinuities such as presence of joints, faults, folds etc. also influence the profile of excavation in a face blast (Verma et al. 2014).

The optimum utilisation of explosive energy for a blast is dependent on the assessment of rock explosive interaction and thereby selecting proper explosive based on the strata demand. The charging parameters and explosive quality has major influence on the breakage pattern from a blast. Mandal et al. (2005) discussed the role of charging parameters and initiation sequence on the blast induced damage pattern. The authors have discussed the impact of detonation time on the magnitude of over break. The detonation velocity of the explosive has been considered as the important parameter by Bullock \& Rostami (2013). The findings have suggested using slower explosive for the blast in spongy (plastic) nature of rock as compared to the brittle nature of rock. The charging quantity, quality along with blast design parameter impacts the fragmentation from a rock blasting operation. Himanshu et al. (2021) have computed the optimal dimensional parameters for underground blast using empirical rock fragmentation models. The excess scattering in the delay detonators have major influence on the profile of breakage in the face blast. The scattering leads to improper detonation of the charged blast holes and thereby influences the creation of required cut for the progressive initiation round. It has been observed that the scattering in delay detonators influences both the pull from the blast as well as enhances the magnitude of over break (Vishwakarma 2020). The profile of excavation in the face blast is being affected by several other parameters such as - the magnitude of deviation in the drill holes, hole spacing etc. (Singh 2018).

Various researchers have used statistical and numerical approach for predictions of blast induced damages. Statistical algorithms such as - neural network, genetic algorithms, colony optimisation algorithm, random decision tree, particle swarm optimisation, support vector machine etc. has been used extensively for prediction of blasting outputs under different scenarios (Rezaeineshat et al. 2020; Saghatforoush et al. 2016; Monjezi et al. 2010; Kumar et al. 2021; Zhang et al. 2020; Hasanipanah et al. 2015). These statistical algorithms are based on the data analysis for the experimental blasts carried out at the site. The numerical models however have advantage of simulating the rock mass conditions of the site with specific parametric condition. The parameters in the 
numerical models can be explicitly distinguished. The respective blasting outputs with the variation of any parameter can be recorded using this approach. Researchers such as Pan et al. (2021), Wang et al. (2018), Onederra et al. (2013), Liu \& Katsabanis (1997) etc. have used numerical simulation approach for assessment of blast induced damages under various conditions. Mitelman \& Elmo (2014) have used a hybrid finite discrete element based modelling approach for prediction of blast induced damage in tunnelling. Xu et al. (2015) predicted blast induced rock fracture near a tunnel using numerical simulation.

\subsection{Explicit Dynamics}

The explicit solver uses the Central Difference Time Integration scheme for computation of nodal acceleration. In this solver, the forces are computed at the nodes (resulting from internal stress, contact, or boundary condition), and the nodal acceleration are derived by dividing forces by mass as per Equation I. Once the nodal acceleration at time $n-1 / 2$ is determined, the nodal velocities at time $n+1 / 2$ is found using Equation II. Thereafter, the final positions of nodes are updated to time $\mathrm{n}+1$ by integrating the velocities as per Equation III.

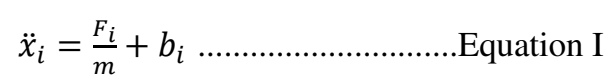

Where, $\ddot{x}_{i}$ are the components of nodal acceleration (i=1,2,3),

$\mathrm{F}_{\mathrm{i}}$ are the forces acting on the nodes,

$b_{i}$ are the components of body acceleration,

$\mathrm{m}$ is the mass of the node

$$
\dot{x}_{i}{ }^{n+1 / 2}=\dot{x}_{i}{ }^{n-1 / 2}+\ddot{x}_{i}{ }^{n} \Delta t^{n} \ldots \ldots \ldots \ldots . . \text { Equation II }
$$

Where, $\dot{x}_{i}$ are the components of nodal velocity $(\mathrm{i}=1,2,3)$

$$
x_{i}^{n=1}=x_{i}^{n}+\dot{x}_{i}^{n+1 / 2} \Delta t^{n+1 / 2} \ldots \ldots \ldots \ldots \ldots \ldots \text { Equation III }
$$

Where, $x_{i}$ are the nodal displacement $(\mathrm{i}=1,2,3)$

The basic equations solved by an Explicit Dynamics solver comprises of conservation of mass, momentum and energy in Lagrange coordinates. The modelled geometry in simulation is given material constitutive models and set of initial and boundary conditions. For Lagrange formulation, the mesh moves and distorts with the modelled material, so conservation of mass is automatically satisfied. The density at any time can be determined from the current volume of the zone and its initial mass. The conservation of momentum is related with the partial differential equations relating the acceleration to the stress tensor $\sigma_{\mathrm{ij}}$ as shown in equations IV, V and VI. Conservation of energy relation is shown in Equation VII. 


$$
\begin{gathered}
\rho \ddot{x}=b_{x}+\frac{\partial \sigma_{x x}}{\partial x}+\frac{\partial \sigma_{x y}}{\partial y}+\frac{\partial \sigma_{x z}}{\partial z} \ldots \ldots \ldots \text { Equation IV } \\
\rho \ddot{y}=b_{y}+\frac{\partial \sigma_{y x}}{\partial x}+\frac{\partial \sigma_{y y}}{\partial y}+\frac{\partial \sigma_{y z}}{\partial z} \ldots \ldots \ldots \text { Equation V } \\
\rho \ddot{z}=b_{z}+\frac{\partial \sigma_{z x}}{\partial x}+\frac{\partial \sigma_{z y}}{\partial y}+\frac{\partial \sigma_{z z}}{\partial z} \ldots \ldots \ldots \text { Equation VI } \\
\text { Where, } \rho \text { is density } \\
\sigma_{i j} \text { are the stress tensors } \\
\ddot{x}, \ddot{y} \text { and } \ddot{z} \text { are acceleration } \\
\mathrm{b}_{\mathrm{i}} \text { are the components of body acceleration } \\
\dot{e}=\frac{1}{\rho}\left(\sigma_{x x} \dot{\varepsilon}_{x x}+\sigma_{y y}+\sigma_{z z} \dot{\varepsilon}_{z z}+2 \sigma_{x y} \dot{\varepsilon}_{x y}+2 \sigma_{y z} \dot{\varepsilon}_{y z}+2 \sigma_{z x} \dot{\varepsilon}_{z x}\right) \ldots \ldots . . . \text { Equation VII } \\
\text { Where, } \dot{e} \text { is energy } \\
\dot{\varepsilon}_{i j} \text { are the strain rates } \\
\ddot{x}, \ddot{y} \text { and } \ddot{z} \text { are acceleration } \\
\mathrm{b}_{\mathrm{i}} \text { are the components of body acceleration, }
\end{gathered}
$$

These conservation equations are solved for each time step. The equations are solved for each element in the model, based on input values at the end of the previous time step.

\subsection{Experimental site details}

The outputs of the numerical simulation results for the optimised relief hole were used to redesign the face blasting pattern at Rajpura Dariba underground Lead-Zinc mine. The geotechnical properties of the rock mass were also tested for the same mine. The mine is located in the southern extremity of Rajpura-Dariba Bethunmi metallogenic belt in Rajsamand district of Rajasthan state of India.

Dariba-Bethumni metallogenic belt comprises an assemblage of medium to high grade metamorphic equivalents of orthoquartzites, carbonates and carbonaceous facies rocks belonging to Bhilwara super group. This cover sequence is underlain by basement rocks (gneisses and schist) of Mangalwar Complex. The Lead-Zinc mineralisation occur in this belt in various sizes and grades. The orebody mainly contains calc-silicate bearing dolomite and graphite mica schist horizons. The geological map of Dariba-Bethumni metallogenic belt is shown in Figure 1 (Sugden et al. 1990; Gupta et al.1995; Mishra et al. 2006). 
The mine area mainly constitutes a sequence of meta-sediments consisting of mics schist, calcareous biotite schist and graphite mica schist (from footwall to hangingwall). Calc-silicate bearing dolomite occurs within the graphite mica schist horizon towards its contact with the calcareous biotite schist.

Figure 1. Geological map of Dariba-Baethumni metallogenic belt (modified after Sugden et al. 1990; Gupta et al. 1995; Mishra et al. 2006).

\subsection{Existing face blasting method employed at the experimental site}

The development face blasting at the mine is carried out to make drivages and cross-cuts. The drivages are made in the contact of the ore body to have the initial access to the ore body. Cross-cuts are usually driven across the ore body. The cross-section of the drivages are generally of $4.0 \mathrm{~m} \times 5.0 \mathrm{~m}$ and $4.5 \mathrm{~m} \times 5.0 \mathrm{~m}$ dimension. The blast holes are drilled in the burn-cut pattern to make the drivages. The burn-cut pattern at the mine incorporates drilling of the blast holes of drill diameter $40 \mathrm{~mm}$ and drilling length of $4.0 \mathrm{~m}$.

\subsection{Numerical simulation to study the parametric response of relief hole variations on breakage pattern in the face blast}

Numerical simulation with varying relief hole diameter and number of relief holes has been carried out using explicit dynamics of Ansys software. The numerical model prepared for this purpose consisted of a block having dimensions of $4.0 \mathrm{~m} \times 5.0 \mathrm{~m} \times 7.0 \mathrm{~m}$. The cross sectional surface of $4.0 \mathrm{~m} \times 5.0 \mathrm{~m}$ was taken as similar to the cross-section of the drivages. The blast holes and relief holes of length $4.0 \mathrm{~m}$ was drilled in the model. The material model for the block was taken as similar to the Lead-Zinc ore bodies of the mine. The tested rock mass properties of the Lead-Zinc Ore body used in the numerical simulation is shown in Table 1.

Table 1. Rock mass properties of Lead-Zinc Ore body used in numerical model.

The numerical models have varying relief hole diameter as- of $40 \mathrm{~mm}, 70 \mathrm{~mm}, 89 \mathrm{~mm}, 105 \mathrm{~mm}$ and $165 \mathrm{~mm}$. The diameter of the charged blast holes was kept $40 \mathrm{~mm}$ in each case. The explosive charge was given under fully coupled condition in the model. The number of relief holes were varied as- one relief hole, two relief holes, three relief holes and four relief holes. A view of arrangement of cut holes (including relief holes (R) and blast holes) is shown in Figure 2. The physical properties of the explosive used in the model follows Jones-Wilkins Lee (JWL) equation of state (EOS). This EOS is used for the detonation products (Castedo et al. 2018; Artero-Guerrero et al 2017; Hu et al 2015; Pramanik \& Deb 2015; Sanchidran \& Lopez 2006). The EOS is a relationship among the pressure, volume and energy. The expression for JWL equation of state is presented in equation VIII. 
$P=A\left(1-\frac{\omega}{R_{1} V}\right) e^{-R_{1} V}+B\left(1-\frac{\omega}{R_{2} V}\right) e^{-R_{2} V}+\frac{\omega E}{V} \ldots \ldots$ Equation VIII

Where,

$\mathrm{A}, \mathrm{B}, \mathrm{R} 1, \mathrm{R} 2$ and $\omega$ are constants

$\mathrm{P}=$ pressure

$\mathrm{V}=$ Volume

$\mathrm{E}=$ Energy

The JWL EOS parameters for the explosive have been used in the model from the literature. Davis \& Hill (2001) has estimated the JWL parameters for Ammonium Nitrate Fuel Oil (ANFO) explosives using cylindrical tests. The parameters simulated in the numerical model are shown in Table 2.

Figure 2. A view of arrangement of cut-holes used in the numerical model.

Table 2. JWL EOS parameters of the explosive used in numerical model.

The stemming portion of the blast holes were given "sand" from the material library of Ansys software (Autodyn Manual v 18.0). The material model used for sand in the model is "MO granular" with pressure hardening, density hardening and linear compaction EOS.

The explicit dynamics module of Ansys consists of Lagrange and Euler domain. The Lagrangian domain is used to model solid part as the meshes in this domain are distorted with the material. The Euler domain is used to model the fluid or gaseous type material (Pita \& Felicelli 2008). In this numerical model, the ore was modelled under Lagrange domain where as explosive and stemming materials were modelled in Euler domain.

The numerical model was given fixed support and impedance boundary conditions along all the faces of the model except the free face. The fixed support was given to restrict the deformations within the rock mass only. The impedance boundary condition works to quit the incoming blast waves.

\subsection{Analysis of the numerical simulation results}

The numerical simulation was carried out for different combinations of relief holes and blast holes in the cut portion of the burn-cut pattern. The deformation pattern under different conditions were plotted and compared to get the optimised pattern. The trend of variation in deformation under different parametric combinations have been studied. 
The deformation pattern recorded as the model output reflects only tensile deformation against the relief holes. The plot of maximum principal elastic strain from a model output is shown in Figure 3. The analysis of maximum principle elastic strain of the rock under blast loading shows that the tensile strain is developed only along the relief holes. This is because the stress wave due to blasting propagates from the detonation point to free face. The free face in burn cut face blasting pattern is along stemming portion and along relief hole. The propagating stress wave in such case is compressive in nature. The stress wave gets reflected from free face under tension. Since the compressive strength of the rock mass is much larger than the tensile strength. The deformation within the rock mass takes place along tension.

Figure 3. Maximum principal elastic strain contour for the blast of cut holes having four relief holes.

The actual blasting of the cut holes includes delay sequence among the holes. However, the simulation with field delay timing in explicit dynamics is not possible. Hence, the blast holes were allowed to be fired simultaneously in the model.

The deformation pattern of the model output was analysed in terms of the pull achieved and the overbreak. The comparative deformation contour along the pull and periphery of the cut holes for two different conditions of relief holes is shown in Figure 4.

Figure 4. Comparison of deformation contour due to blast of burn cut development face having relief holes of 40 $\mathrm{mm}$ and $165 \mathrm{~mm}$ diameter.

The comparison reveals that there is minimal deformation along pull as well as periphery direction in the burn cut pattern having relief holes of $40 \mathrm{~mm}$ diameter as compared to the pattern having relief holes of $165 \mathrm{~mm}$ diameter. The deformation contour was plotted along with the scale and the attempt was made to assess the extent of deformation. However, it was realised that the plotted contour doesn't include all the area that has been deformed. The plot will show no deformation, even if there is deformation in the model but the magnitude of deformation is less than the second lowest value in the contour band. Isosurface of zero-deformation was plotted to address this issue. An Isosurface is a surface that represents points of constant value within a volume of space. Isosurface plots of non-deformed zones for burn cut face blast with four relief holes of different diameter is shown in Figure 5. 
The comparison of the void spaces in the plot shows that the extent of deformation increases with increment in the diameter of the relief holes.

Figure 5. Isosurface plot of non-deformed zones for burn cut development face blasts with relief holes of different diameter.

To further investigate the exact extent of breakage under different conditions, capped isosurfaces of zero deformation were plotted. The capped isosurface is the isosurface with capping on the void portion. The capped isosurface for all the parametric conditions were plotted along explosive charging and periphery of blast holes' directions. The analysis of capped isosurface along explosive charging direction suggests that the complete deformation in the rock mass upto charge length doesn't takes place when the relief hole diameter is $40 \mathrm{~mm}$. The complete deformation is observed under all other conditions with different relief hole diameter. The comparative isosurface plot along explosive charging direction with the assessment of deformation extent under two different conditions is shown in Figure 6.

Figure 6. Comparison of capped isosurface plot along explosive charging direction for burn cut development face blast with relief holes of $40 \mathrm{~mm}$ and $70 \mathrm{~mm}$ diameter.

The capped isosurface has also been plotted to investigate the extent of damage along the periphery of the cut blast holes. The plotted isosurface under different variations of relief holes is shown in Figure 7. The extent of deformation from the plot has been assessed using image analysis. It can also be seen from the plot that the capping consists of coloured contour. The contour represents the higher magnitude of deformation. The comparison of contour reveals that the maximum deformation occurs around the relief holes. The deformation extent is enlarged with the increment in the number of relief holes. The analysis of contour for the model with relief hole diameter of $40 \mathrm{~mm}$ shows the uniform deformation along blast holes as well as relief holes. This is due to the same free face provided by relief holes as well as charged holes in stemming portion. The figure shows that the tensile stress wave produces deformation at much larger extent when the diameter of relief holes is $165 \mathrm{~mm}$.

Figure 7. Plot of capped isosurface along the periphery of the cut blast holes for burn cut development face blast under different variations of relief holes. 
The analysed extent of deformation under different variants of relief holes is shown in Figure 8 . The comparison suggests that the extent of deformation increases with the increment in the number and diameter of relief holes. The figure also suggests that the extent of deformation is larger in case of a single large relief hole than using multiple relief holes of smaller diameter. Accordingly, it can be concluded that after achieving the complete pull from the burn cut face blast, multiple numbers of smaller diameter relief holes will give more controlled deformation than the single large diameter relief hole.

Figure 8. Comparison of extent of deformation in rock mass for burn cut development face blast under different variations of relief holes.

The maximum magnitude of deformation occurred in the rock mass under different conditions has also been compared. The trend of maximum deformation under different conditions is shown in Figure 9. The trend shows that the magnitude of deformation increases with the increment in the number and diameter of relief holes. The increment trend is sharper for the case of increase in the diameter of relief holes as compared to that of the numbers of relief holes.

Figure 9. Comparison of maximum deformation output from the numerical model for burn cut development face blast under different variations of relief holes.

\subsection{Redesigning of blasting pattern using simulation results}

The existing blast design pattern practiced at the experimental site was redesigned using the simulation results. View of a development face blast of the study site is shown in Figure 10. The existing burn cut blasting pattern at the site consists of 56 charged blast holes of $40 \mathrm{~mm}$ diameter with 04 relief holes of $89 \mathrm{~mm}$ diameter. There were issues of socket formation as well as overbreak from the face blast at the site. The existing drilling and delay pattern practiced at the mine is shown in Figure 11. The identification of sockets was done to investigate the cause of its formation. The most of the socket were in the holes nearby of the cut portion, which reveals that there was overbreak while blasting of the cut portion. This overbreak might have caused to restrict the detonation of the nearby charged blastholes, which have resulted into the socket formation. The extent of damage output from the numerical model has been compared to estimate the optimum cut blasting pattern to reduce the deformation due to the blast of cut holes. The extent of deformation output from the numerical model is due to simultaneous 
detonation of thirteen blast holes. The numerical simulation with the practical delay timing is not possible with Ansys-Explicit Dynamics module. Hence, the simultaneous detonation was provided in the model to all the cut blast holes. Based on the dependency of rock breakage on critical peak particle velocity (Holmberg \& Persson 1978), the blast induced deformation can be considered proportional to the maximum charge weight per delay. Accordingly, the deformation while firing of two blastholes of cut simultaneously will be $1 / 6.5^{\text {th }}$ of that of the simulation results. The extent of deformation using this computation for firing of two cut holes simultaneously against four relief holes of $115 \mathrm{~mm}$ diameter will be 2.4 square meter. Accordingly, the deformation will be 0.1 $m$ more than the cut boundary extent using this pattern. Hence, this pattern can be considered as optimum for the blasting face of the study site.

Figure 10. view of a burn cut face at the experimental site.

Figure 11. Existing drilling and blasting pattern practiced at the experimental development face of the mine.

The nearfield vibration was monitored for the experimental blasts at the site by placement of seismograph. The waveform analysis of recorded near field vibration data has been carried out to explore the possibility of design modifications for reduction of overbreak. The recorded waveform for an experimental development face blast is shown in Figure 12. The analysis of the recorded waveform shows two sharp peaks of vibration. One peak is due to the blast of cut holes and another peak is due to the blast of perimeter holes. The vibration peaks have been compared with the face blasting pattern shown in Figure 11. The peak due to the blast of cut holes is due to firing of four cut holes simultaneously against the insufficient free face generated by relief holes of $89 \mathrm{~mm}$ diameter. The peak due to firing of perimeter holes can be considered as the main reason behind the overbreak due to the blast. The review of the existing blast design reveals that the number of holes blasted at delay no. 18 \& 19 is 16 \& 15 respectively, which is much larger to increase the charge weight per delay thereby increasing vibration in the nearby of line of extraction in the development face. The increased level of vibration will result into enhanced over break. So, the design was modified to distribute the delay sequence such that the charge weight per delay along periphery holes should be reduced.

Figure 12. Recorded waveform for the experimental blast featuring the delay timings of the blast holes. 
The revised blast design based on the results of waveform analysis and numerical simulation is shown in Figure 13. The blast design consists of four relief holes of $115 \mathrm{~mm}$ diameter. The firing of only two cut blast holes simultaneously was suggested in the revised blast design. However, maximum 8 blast holes were suggested to be fired in the blast design, thereby reducing the maximum charged weight per delay by half.

Figure 13. Revised blast design based on the results of the numerical simulation and waveform analysis.

The results of the experimental trials under existing and revised blast design patterns were compared. The comparison has also been made with variations in numbers of relief holes. A view of the cut blast face with three and four numbers of relief holes is shown in Figure 14. The relief hole diameter was varied as $89 \mathrm{~mm}$ and 115 mm. Altogether twenty blasts were conducted to compare the results. The blasting outputs under different conditions is shown in Table 3. The outcomes have been measured in terms of pull achieved and overbreak generated. The results show that there are considerable improvements in the pull and reduction of socket formation while using four relief holes of $115 \mathrm{~mm}$ diameter. Although, the overbreak generation is mainly influenced by the charging pattern in periphery holes. But, the controlled movement of the face after blast of each cut also contributes in the overbreak reduction. Accordingly, the revised pattern has also addressed the issue of overbreak generation.

Figure 14. Cut hole pattern with three and four relief holes.

Table 3. Blasting outputs from the experimental blasts conducted at the site.

The resulting nearfield vibration has also been reduced with the revised blast design. The waveform of nearfield vibration recorded at a distance of $30 \mathrm{~m}$ from the blast face with the revised blast design is shown in Figure 15 . The analysis shows that the vibration magnitude has come down to $10 \mathrm{~mm} / \mathrm{s}$ as compared to $40 \mathrm{~mm} / \mathrm{s}$ vibration shown in Figure 12. The waveform analysis also reveals that the variation in magnitude of vibration while blasting of different cuts is relatively uniform. This leads to the controlled deformation of the rock mass.

Figure 15. Recorded waveform for the experimental trial with the revised blast design pattern.

\subsection{Conclusions}

The number and diameter of relief holes plays pivotal role in blast induced deformation pattern of a burn cut blast. The relief hole works as the free face to ensure tensile breakage of the rock mass under the blast loading. 
Numerical simulation and analysis of parametric response for different combinations of relief holes is capable of optimising the burn cut blast design pattern. Accordingly, the numerical simulation approach with finite element based modeller Ansys-Explicit dynamics was used in this study. The deformation prediction under different scenario has been made for a lead-zinc mine site. The model was simulated for blast of cut holes with different relief hole combinations. The model was provided with isotropic elastic rock mass condition. The explosive parameters were modelled under JWL equation of state. The model result shows that the deformation in rock increases with the increment in the number and diameter of the relief holes. The comparative analysis of the deformation shows that the larger number of relief holes with small diameter gives more controlled deformation than the single relief hole of large diameter. The numerical modelling based output has been used to redesign the existing blast design of the experimental site. The assessment of extent of deformation from numerical modelling shows that the four number of relief holes with diameter of $115 \mathrm{~mm}$ is optimum for the modelled rock mass condition. The number of cut blast holes firing simultaneously should not be more than two in order to get the optimum breakage. The waveform analysis of the recorded nearfield vibration from experimental site was also carried out. Two dominant peaks of vibration were observed in the recorded waveform. The peaks were due to the blasts of cut holes and periphery holes. The peak in cut blast hole region is due to the insufficient movement of rock mass under four relief holes of $89 \mathrm{~mm}$ diameter. The peak due to blast of periphery holes is because of larger number of blast holes firing at a delay. The blast design pattern was revised based on the results of numerical simulation and waveform analysis. The overbreak reduction has been achieved using the revised blast design pattern. The issues of socket formation have also been addressed with the revised pattern.

The methodology used in this paper can be used to optimise blast design parameters for a face/tunnel blast. Since, the blasting output is strata dependent, the numerical simulation can be a useful tool to give the insight about the optimum blast design for a face/tunnel blast.

\section{Acknowledgements}

Authors would like to thank Director, CSIR-CIMFR for giving permission and necessary support for writing paper. The necessary support by the mine management of Rajpura Dariba Mine of M/s Hindustan Zinc Limited during the experimental trials is also thankfully acknowledged. The support of Dr. Ravi Shankar, Project Assistant of CSIR-CIMFR is thankfully acknowledged.

\section{Conflict of interest statement}

On behalf of all authors, the corresponding author states that there is no conflict of interest 


\section{References}

Abdel-Meguid M, Rowe RK, Lo KY (2003) Three-dimensional analysis of unlined tunnels in rock subjected to high horizontal stress. Can Geotech J.40.1208-24. https://doi.org/10.1139/t03-057.

Adhikari GR, Babu R (1994) Controlled blasting in tunnel - some issues. Tras Inst f Eng (I). MN 75: 56.

Allen RM (2014) An analysis of burn cut pull optimization through varying relief hole depths.

Ansys Autodyn Manual v 18.0.

Artero-Guerrero J, Pernas-Sánchez J, Teixeira-Dias F (2017) Blast wave dynamics: The influence of the shape of the explosive. J Hazard Mater.331:189-99. https://doi.org/10.1016/j.jhazmat.2017.02.035.

Bieniawski ZT (1968) Fracture dynamics of rock. Int J Fract Mech.4. https://doi.org/10.1007/BF00186807.

Bullock RL, Rostami J (2013) Tunneling and Underground Construction.

Castedo R, Natale M, López LM, Sanchidrián JA, Santos AP, Navarro J (2018) Estimation of Jones-Wilkins-Lee parameters of emulsion explosives using cylinder tests and their numerical validation. Int $\mathrm{J}$ Rock Mech Min Sci.112: 290-301. https://doi.org/10.1016/j.ijrmms.2018.10.027.

Davis LL, Hill LG (2001) ANFO Cylinder Tests, Shock Comp. of Cond. Matter - 2001. Conf. Am. Phy. Soc. Top. Gr. Shock Compr. Cond. Matter. $620: 165-168$.

Ding YQ, Tang WH, Zhang RQ RX (2013) Determination and Validation of Parameters for Riedel-HiermaierThoma Concrete Model. Def Sci J.63(5) :524-530. https://doi.org/10.144029/dsj.63.3866.

Gupta RN, Singh RB, Adhikari GR, Singh B (1988) Controlled blasting for underground excavations. Int. Symp. Undergr. Eng. 449-58.

Gupta SN, Arora YK, Mathur RK, Iqbaluddin B, Prasad B, Sahni TN, Sharma SB (1995) Geological map of the Precambrians of the Aravalli region. southern Rajasthan and northeastern Gujarat. India (4 sheets. scale 1: 250,000). Geol. Surv. India.

Hasanipanah M, Monjezi M, Shahnazar A, Jahed Armaghani D, Farazmand A (2015) Feasibility of indirect determination of blast induced ground vibration based on support vector machine. Measurement.75: $289-97$. https://doi.org/10.1016/j.measurement.2015.07.019.

Himanshu VK, Roy MP, Shankar R, Mishra AK, Singh PK (2021) Empirical Approach Based Estimation of Charge Factor and Dimensional Parameters in Underground Blasting. Mining, Metallurgy \& Exploration. 38:1059-1069.https://doi.org/10.1007/s42461-020-00374-8.

Holmberg R, Persson PA (1978) The Swedish approach to contour blasting. Proceedings of. 4th Annu. Conf. Explos. Blasting Res. Int. Soc. Explos. Eng.113-27.

Hu Y, Lu W, Chen M, Yan P, Zhang Y (2015) Numerical simulation of the complete rock blasting response by SPH-DAM-FEM approach. Simul Model Pract Theory.56 :55-68. https://doi.org/10.1016/j.simpat.2015.04.001.

Kumar S, Mishra AK, Choudhary BS (2021) Prediction of back break in blasting using random decision trees. Eng Comput. https://doi.org/10.1007/s00366-020-01280-9.

Liu L, Katsabanis PD (1997) Development of a continuum damage model for blasting analysis. Int J Rock Mech Min Sci.34: 217-31. https://doi.org/10.1016/S0148-9062(96)00041-1.

Mandal S K, Singh M M, Bhagat N K, Das Gupta S (2005) Causes of overbreak and Influence of Blast parameters for Smooth Undamaged Wall. Int. Symp. Adv. Min. Technol. Manag. IIT. Kharagpur. 49-58.

Mandal SK, Singh MM (2009) Evaluating extent and causes of overbreak in tunnels. Tunn Undergr Sp Technol. 24:22-36. https://doi.org/https://doi.org/10.1016/j.tust.2008.01.007. 
Mishra B, Upadhyay D, Bernhardt HJ (2006) Metamorphism of the host and associated rocks at the RajpuraDariba massive sulfide deposit. Northwestern India. J Asian Earth Sci. 26:21-37. https://doi.org/10.1016/j.jseaes.2004.09.012.

Mitelman A, Elmo D (2014). Modelling of blast-induced damage in tunnels using a hybrid finite-discrete numerical approach. J Rock Mech Geotech Eng.6:565-73. https://doi.org/10.1016/j.jrmge.2014.09.002.

Monjezi M, Ahmadi M, Sheikhan M, Bahrami A, Salimi AR (2010) Predicting blast-induced ground vibration using various types of neural networks. Soil Dyn Earthq Eng.30:1233-6. https://doi.org/10.1016/j.soildyn.2010.05.005.

Murthy VMSR, Dey K (2002) Development of predictive models for blast-induced rock damage assessment (BIRD) in tunnels. MHRD Project No: MHRD (27)/99-00/111/ME: 12-43.

Onederra IA, Furtney JK, Sellers E, Iverson S (2013) Modelling blast induced damage from a fully coupled explosive charge. Int J Rock Mech Min Sci.58:73-84. https://doi.org/10.1016/j.ijrmms.2012.10.004.

Pan C, Li X, Li J, Zhao J (2021) Numerical investigation of blast-induced fractures in granite: insights from a hybrid LS-DYNA and UDEC grain-based discrete element method. Geomech. Geophys. Geo-energ. Georesour. 7:49. https://doi.org/10.1007/s40948-021-00253-6.

Pita C, Felicelli SD (2008) Applications of the immersed element-free Galerkin method. Methods Their Appl.XXVII.10-3.

Pramanik R, Deb D (2015) Implementation of Smoothed Particle Hydrodynamics for Detonation of Explosive with Application to Rock Fragmentation. Rock Mech Rock Eng.48:1683-98. https://doi.org/10.1007/s00603-014$0657-\mathrm{y}$.

Rezaeineshat A, Monjezi M, Mehrdanesh A, Khandelwal M (2020) Optimization of blasting design in open pit limestone mines with the aim of reducing ground vibration using robust techniques. Geomech. Geophys. Geoenerg. Geo-resour. 6:40. https://doi.org/10.1007/s40948-020-00164-y.

Saghatforoush A, Monjezi M, Shirani Faradonbeh R, Jahed Armaghani D (2016) Combination of neural network and ant colony optimization algorithms for prediction and optimization of flyrock and back-break induced by blasting. Eng Comput.32:255-66. https://doi.org/10.1007/s00366-015-0415-0.

Sanchidrián JA, López LM (2006) Calculation of the Energy of Explosives with a Partial Reaction Model. Comparison with Cylinder Test Data. Propellants. Explos Pyrotech.31:25-32. https://doi.org/10.1002/prep.200600003.

Sharma PD (2005) Tunnel Blasting - Emulsion Explosives and Proper Blast Design are the Prerequisite for Better Efficiency. Indian J Mines. Met Fuel.10.

Singh S (2018) Overbreak control in underground mines. Rock Mech Open Access J.1(1): 11-17.

Singh SP (1995) Mechanism of cut blasting. Trans Inst Min Metall.104: A1 134-138.

Sugden T, Deb M, Windley BF (1990) Tectonic setting of mineralization in the Proterozoic Aravalli-Delhi orogenic belt, northwestern India. in. Naqvi. S.M. (Ed.). Precambrian Continental Crust and its Economic Resources Developments of Precambrian Geology. Elsevier, Amsterdam.367-90.

Verma Harsh Kumar, Samadhiya Narendra Kumar, Singh Mahendra, Ramana Vilugundam Venkat (2014) Blast Induced Damage to Surrounding Rock Mass in an Underground Excavation. J Geol Resour Eng.2. https://doi.org/10.17265/2328-2193/2014.01.002.

Verma HK, Samadhiya NK, Singh M, Goel RK, Singh PK (2018) Blast induced rock mass damage around tunnels. Tunn Undergr Sp Technol. 71:149-58. https://doi.org/10.1016/j.tust. 2017.08.019.

Verma HK, Samadhiya NK, Singh M, Prasad VVR, Goel RK (2016) Investigations of Rock Mass Damage Induced by Blasting. J Rock Mech Tunn Technol. 22:2016-65.

Vishwakarma AK, Himanshu VK, Kumar S, Roy MP (2020) Overbreak control in development face blasting of underground metal mine- a case study. Proc. Natl. Conf. Adv. Min. 473-82. 
Wang J, Yin Y, Esmaieli K (2018) Numerical simulations of rock blasting damage based on laboratory-scale experiments. J Geophys Eng.15: 2399-417. https://doi.org/10.1088/1742-2140/aacf17.

Xiao SY, Su LJ, Jiang YJ, Liu ZX (2019). Numerical analysis of hard rock blasting unloading effects in high in situ stress fields. Bull Eng Geol Environ.78: 867-75. https://doi.org/10.1007/s10064-017-1067-7.

Xu L, Schreyer H, Sulsky D (2015) Blast-induced rock fracture near a tunnel. Int J Numer Anal Methods Geomech.39: 23-50. https://doi.org/10.1002/nag.2294.

Zhang X, Nguyen H, Bui XN, Tran QH, Nguyen DA, Bui DTet al. (2020) Novel Soft Computing Model for Predicting Blast-Induced Ground Vibration in Open-Pit Mines Based on Particle Swarm Optimization and XGBoost. Nat Resour Res.29: 711-21. https://doi.org/10.1007/s11053-019-09492-7. 
Figures

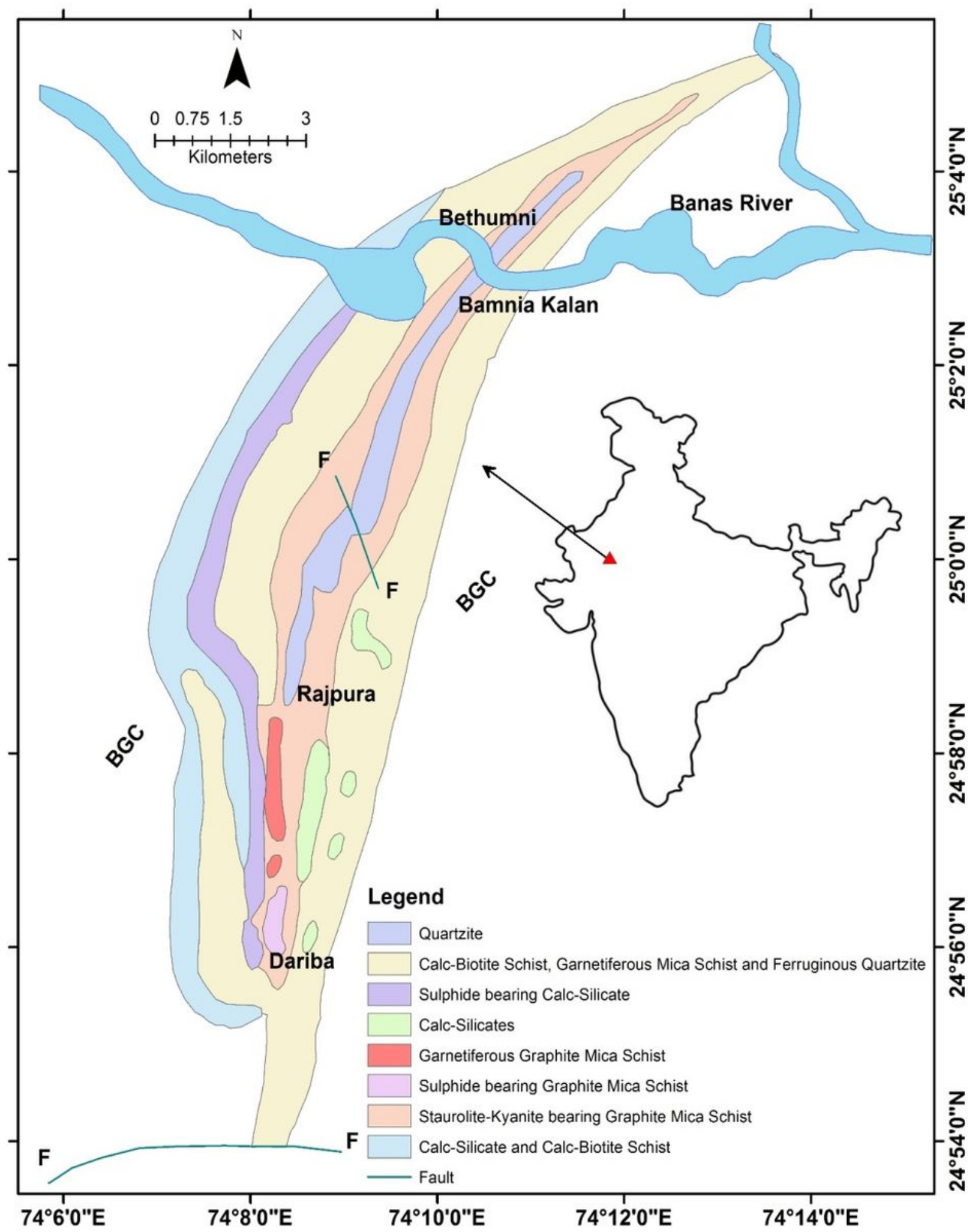

Figure 1

Geological map of Dariba-Baethumnimetallogenic belt(modified after Sugden et al., 1990; Gupta et al., 1995; Mishra et al. 2006). Note: The designations employed and the presentation of the material on this map do not imply the expression of any opinion whatsoever on the part of Research Square concerning 
the legal status of any country, territory, city or area or of its authorities, or concerning the delimitation of its frontiers or boundaries. This map has been provided by the authors.
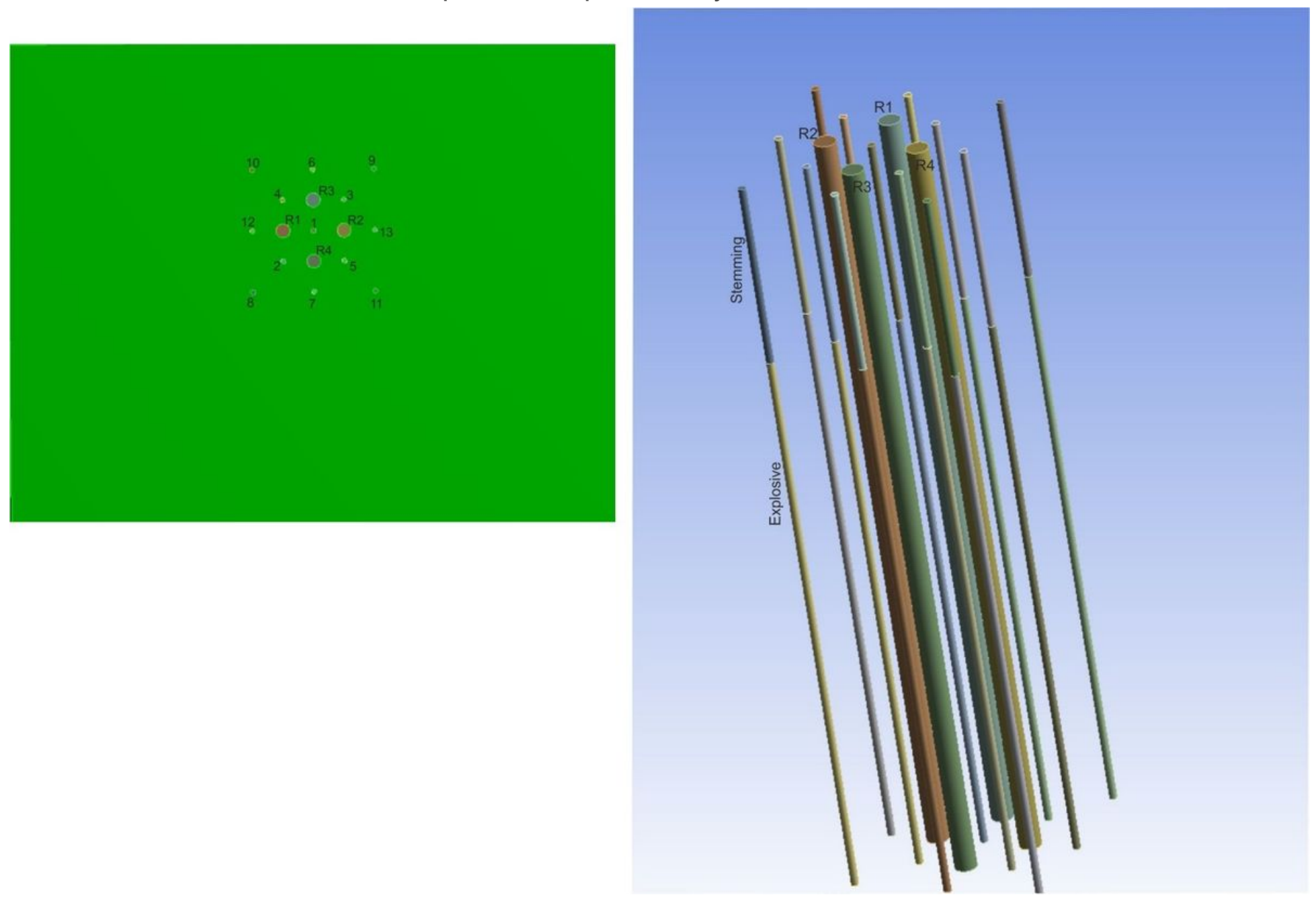

Figure 2

A view of arrangement of cut-holes used in the numerical model. 

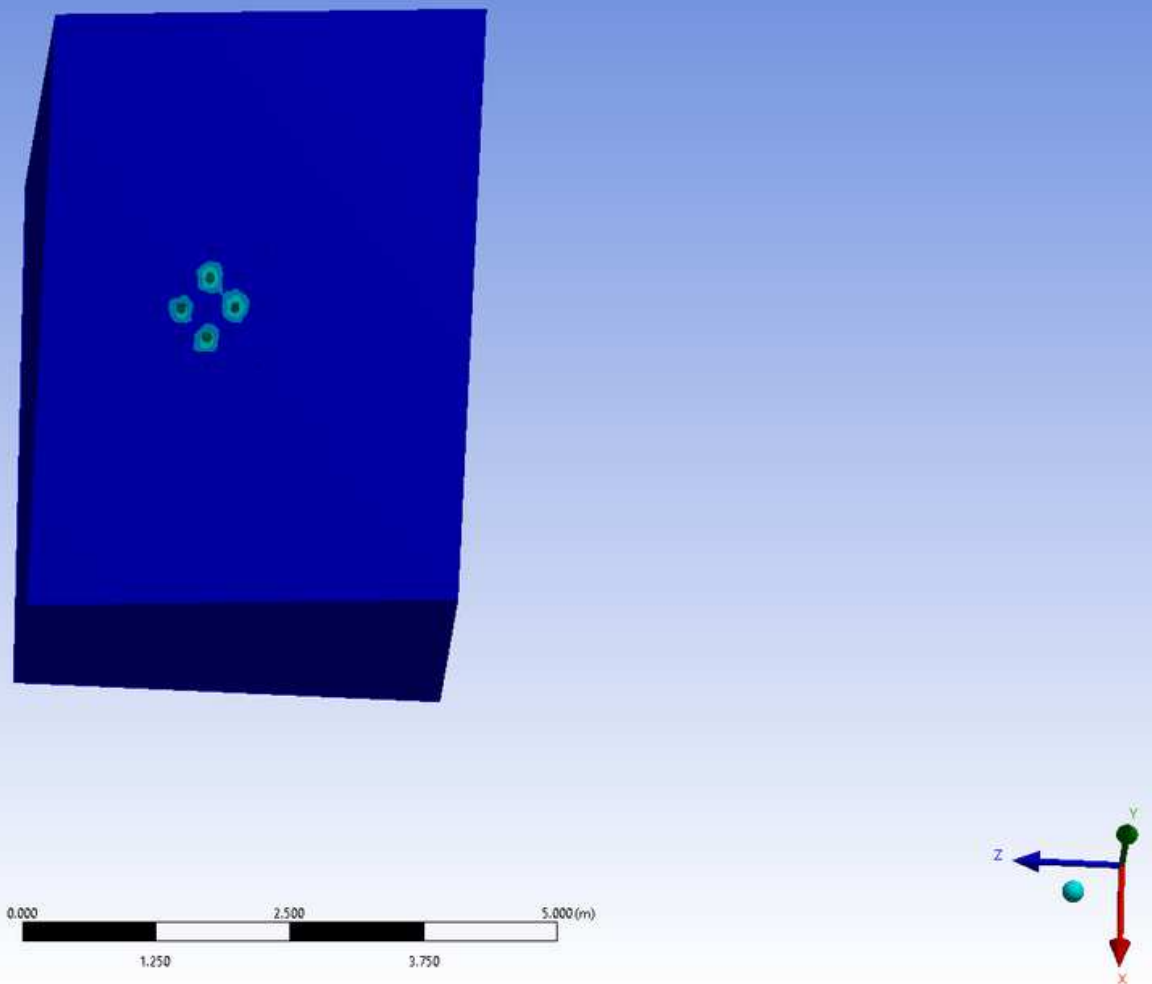

Figure 3

Maximum principal elastic strain contour for the blast of cut holes having four relief holes. 


A: Explicit Dynamics
Total Deformation
Type: Total Deformation
Unit: m
Time: $1.0001 \mathrm{e}-003$
Cycle Number: 1319
25-03-2020 04:30 PM
$\begin{aligned} & 1.8445 \mathrm{e}-9 \mathrm{Max} \\ & 1.6396 \mathrm{e}-9 \\ & 1.4346 \mathrm{e}-9 \\ & 1.2297 \mathrm{e}-9 \\ & 1.0247 \mathrm{e}-9 \\ & 8.198 \mathrm{e}-10 \\ & 6.1485 \mathrm{e}-10 \\ & 4.099 \mathrm{e}-10 \\ & 2.0495 \mathrm{e}-10 \\ & 0 \text { Min }\end{aligned}$
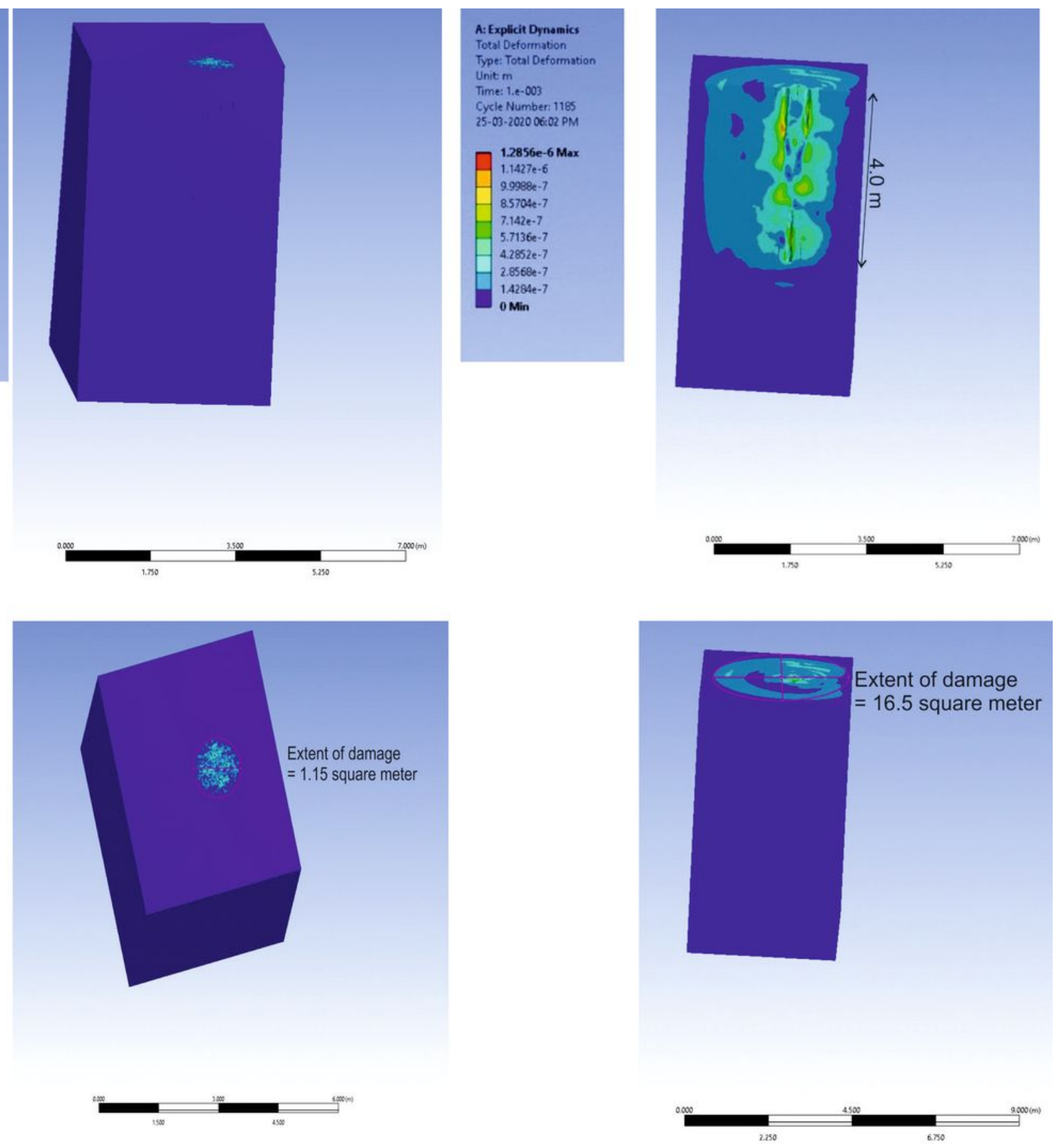

(a) 4 relief holes of $40 \mathrm{~mm}$ each

(b) 4 relief holes of $165 \mathrm{~mm}$ each

\section{Figure 4}

Comparison of deformation contour due to blast of burn cut development face having relief holes of 40 $\mathrm{mm}$ and $165 \mathrm{~mm}$ diameter. 


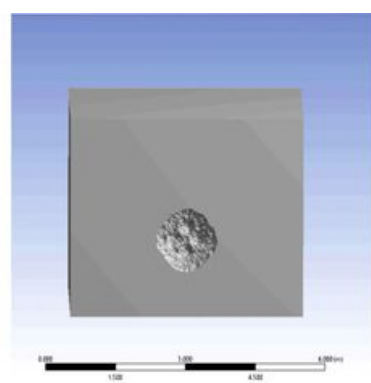

(a) $40 \mathrm{~mm}$

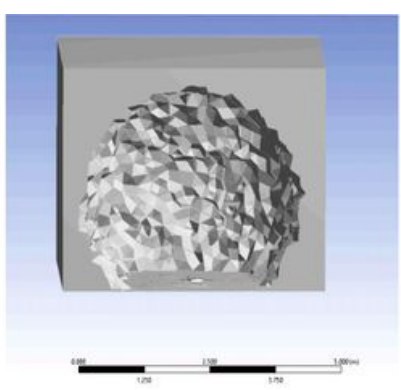

(b) $70 \mathrm{~mm}$
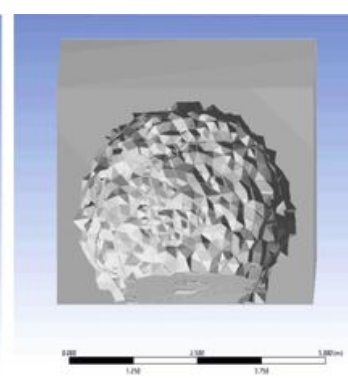

(c) $89 \mathrm{~mm}$

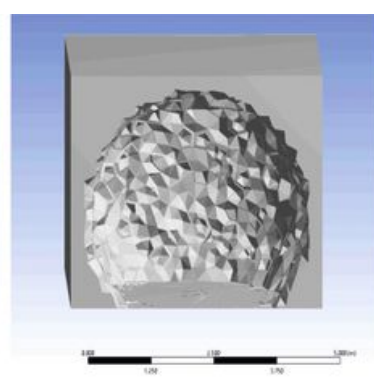

(d) $115 \mathrm{~mm}$

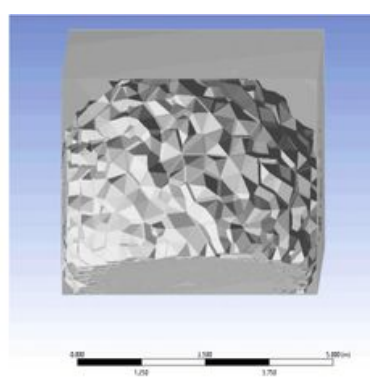

(e) $165 \mathrm{~mm}$

\section{Figure 5}

Isosurface plot of non-deformed zones for burn cut development face blasts with relief holes of different diameter.

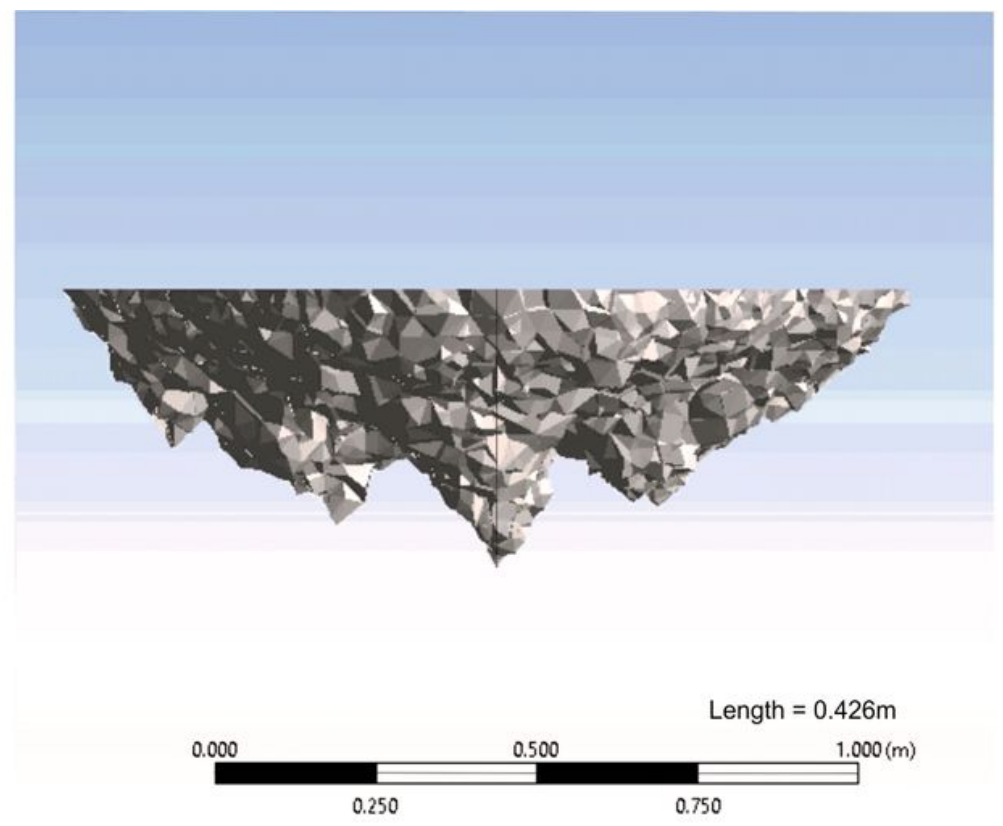

(a) Four relief holes of $40 \mathrm{~mm}$ diameter

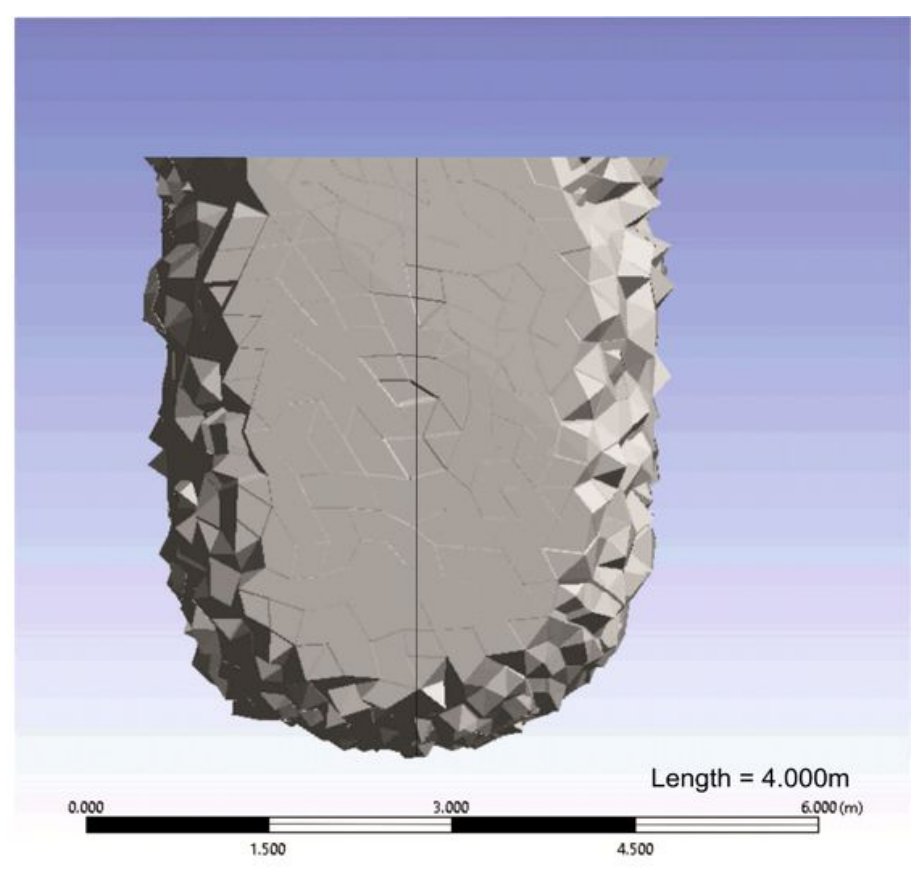

(b) Four relief holes of $70 \mathrm{~mm}$ diameter

\section{Figure 6}

Comparison of capped isosurface plot along explosive charging direction for burn cut development face blast with relief holes of $40 \mathrm{~mm}$ and $70 \mathrm{~mm}$ diameter. 

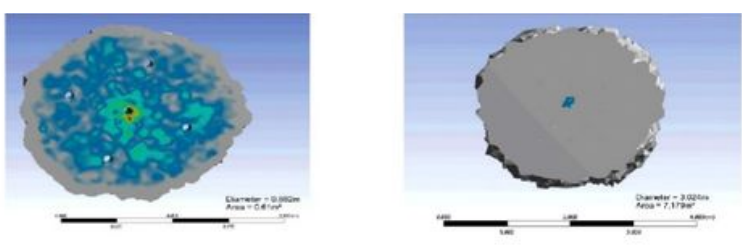

(a) One relief hole of $40 \mathrm{~mm}$ diameter

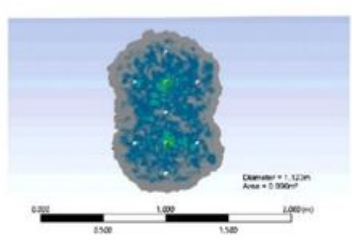

(f) Two relief holes of $40 \mathrm{~mm}$ diameter

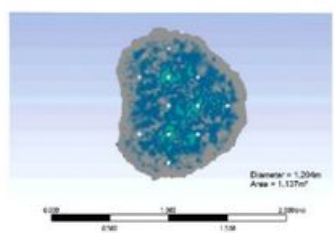

(k) Three relief holes of $40 \mathrm{~mm}$ diameter

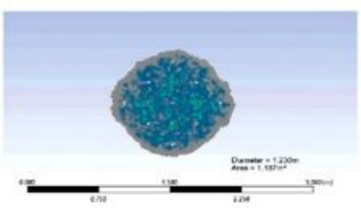

(p) Four relief holes of $40 \mathrm{~mm}$ diameter (b) One relief hole of $70 \mathrm{~mm}$ diameter

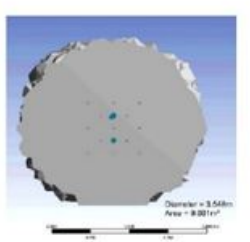

(g) Two relief holes of $70 \mathrm{~mm}$ diameter

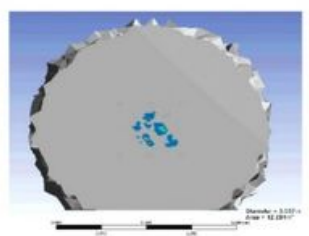

(1) Three relief holes of $70 \mathrm{~mm}$ diameter

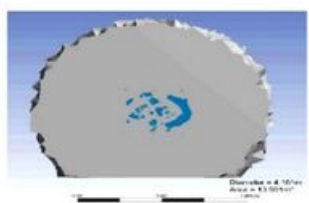

(q) Four relief holes of $70 \mathrm{~mm}$ diameter

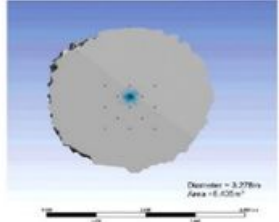

(c) One relief hole of $89 \mathrm{~mm}$ diameter

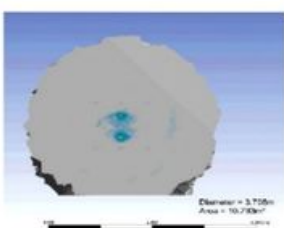

(h) Two relief holes of $89 \mathrm{~mm}$ diameter

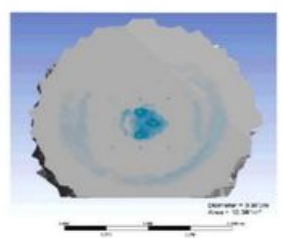

(m) Three relief holes of $89 \mathrm{~mm}$ diameter

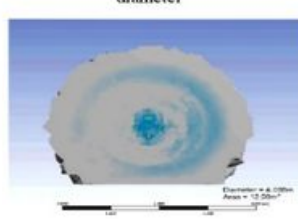

(r) Four relief holes of $89 \mathrm{~mm}$ diameter

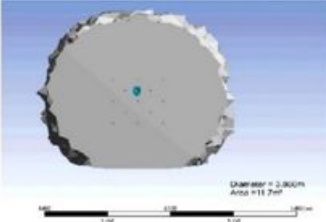

(d) One relief hole of $115 \mathrm{~mm}$ diameter

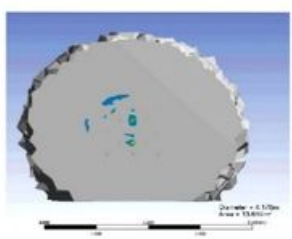

(i) Two relief holes of $115 \mathrm{~mm}$ diameter

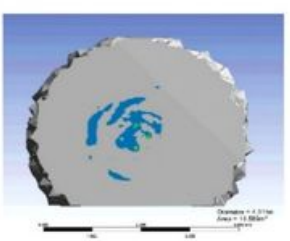

(n) Three relief holes of $115 \mathrm{~mm}$ diameter

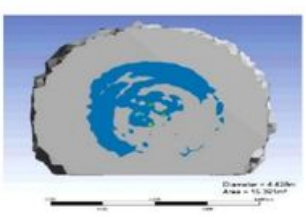

(s) Four relief holes of $115 \mathrm{~mm}$ diameter

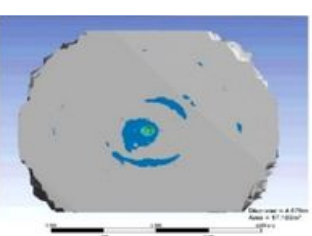

(e) One relief hole of $165 \mathrm{~mm}$ diameter

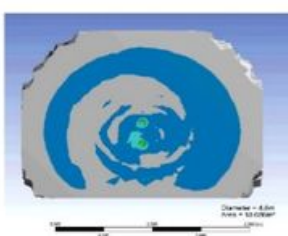

(i) Two relief holes of $165 \mathrm{~mm}$ diameter

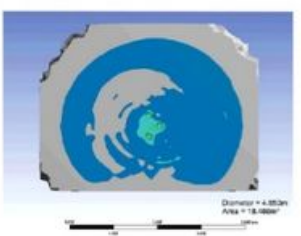

(o) Three relief holes of $165 \mathrm{~mm}$ diameter

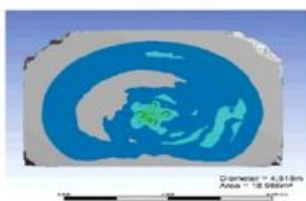

(1) Four relief holes of $165 \mathrm{~mm}$ diameter

\section{Figure 7}

Plot of capped isosurface along the periphery of the cut blast holes for burn cut development face blast under different variations of relief holes. 


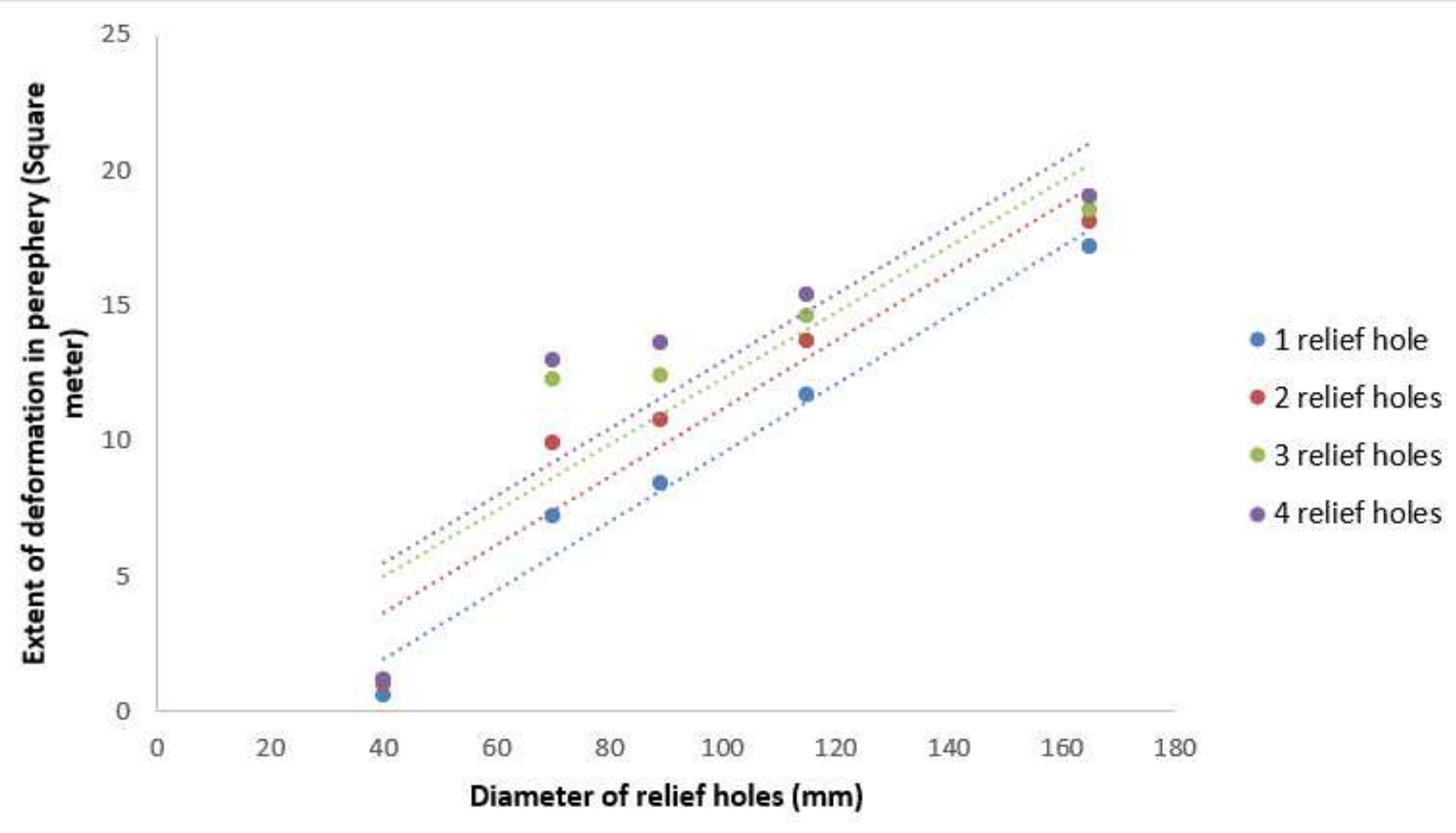

Figure 8

Comparison of extent of deformation in rock mass for burn cut development face blast under different variations of relief holes. 


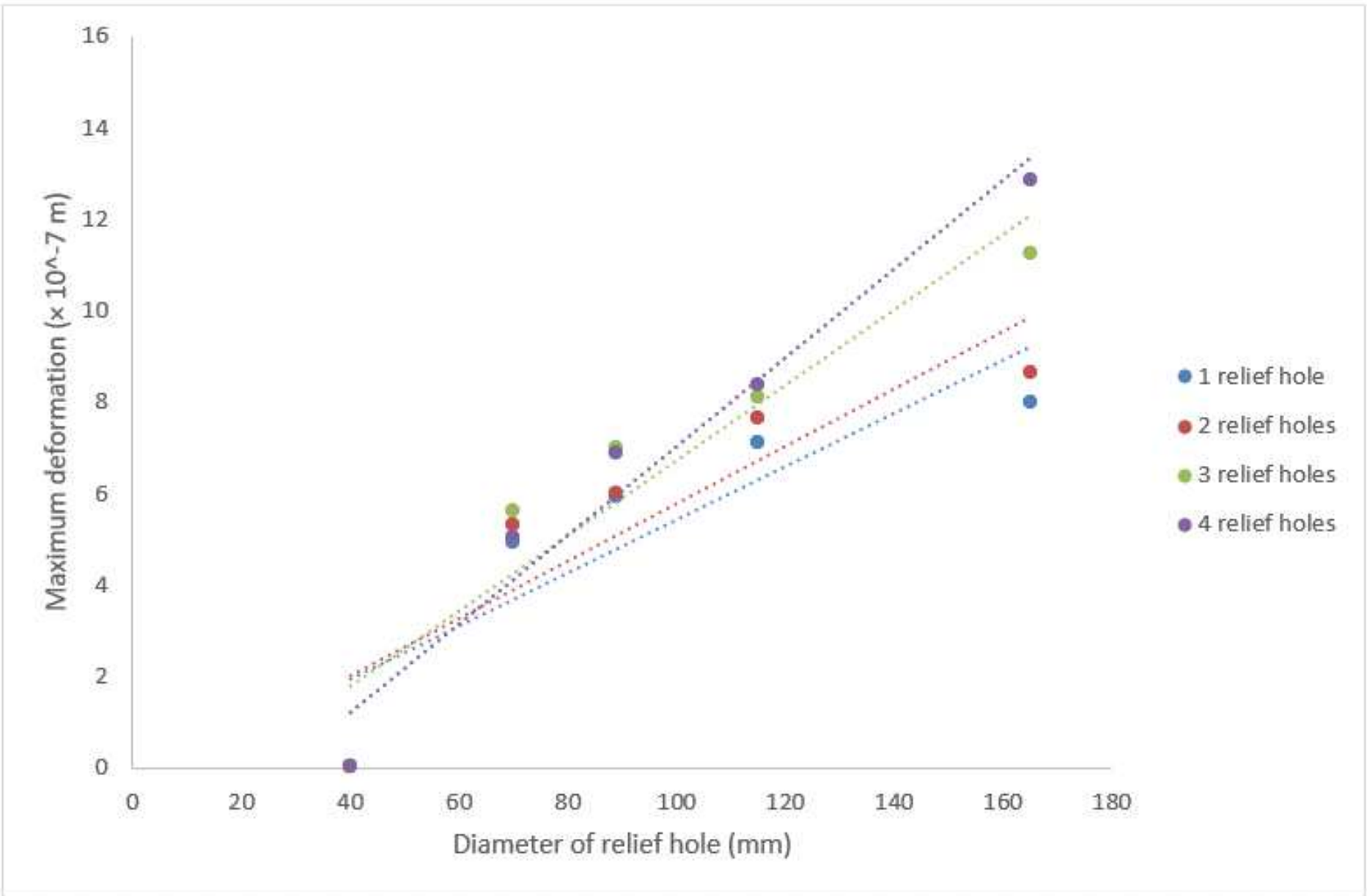

Figure 9

Comparison of maximum deformation output from the numerical model for burn cut development face blast under different variations of relief holes. 


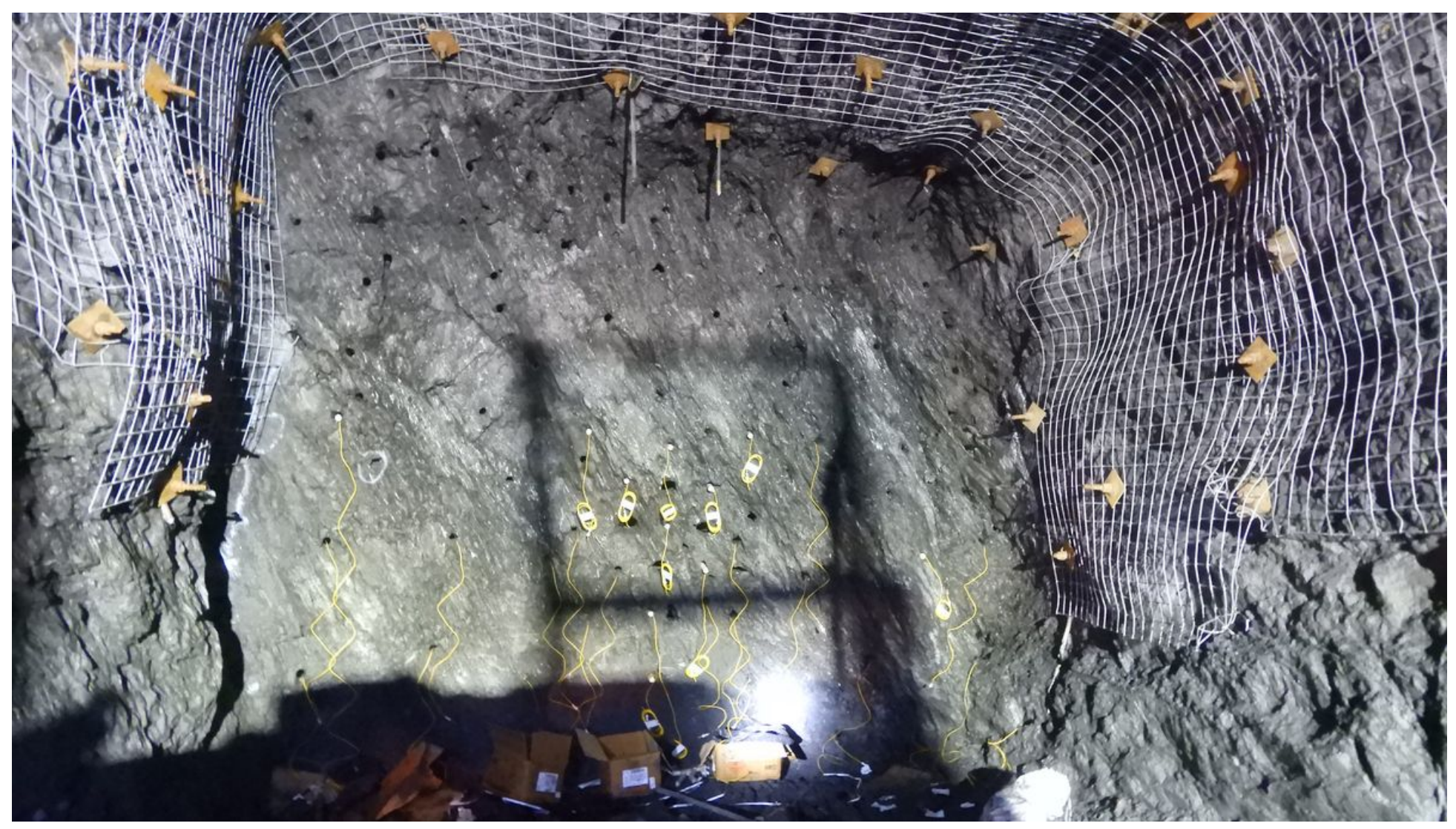

Figure 10

View of a burn cut face at the experimental site.

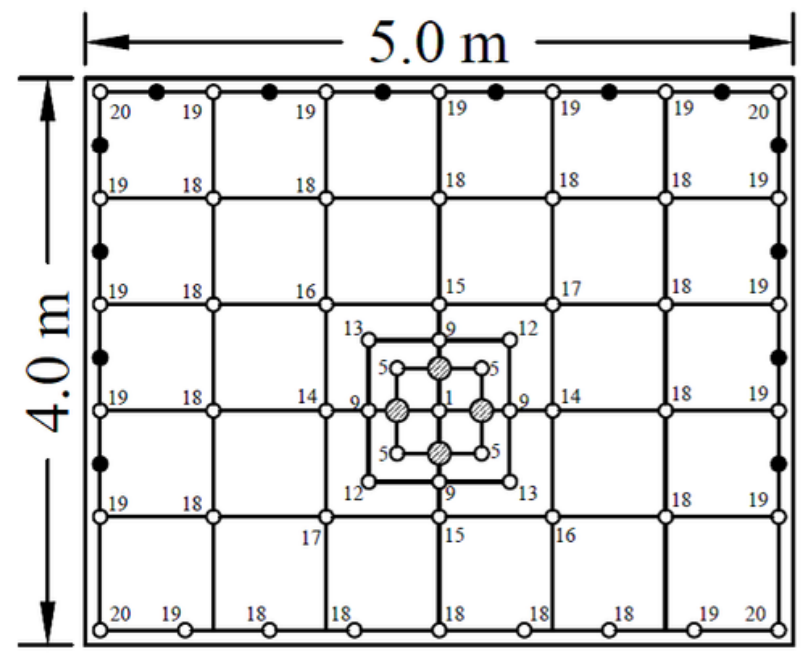

O Charged Hole ( $40 \mathrm{~mm}$ diameter)

- Uncharged Hole ( $40 \mathrm{~mm}$ diameter)

Relief Hole ( $115 \mathrm{~m}$ diameter)

\begin{tabular}{|l|l|c|c|c|c|c|c|c|c|c|c|c|c|c|c|}
\hline $\begin{array}{l}\text { Delay } \\
\text { No }\end{array}$ & $\begin{array}{l}\text { Pre Split } \\
\text { Holes }\end{array}$ & $\begin{array}{l}\text { Relief } \\
\text { Holes }\end{array}$ & 01 & 05 & 09 & 12 & 13 & 14 & 15 & 16 & 17 & 18 & 19 & 20 & $\begin{array}{l}\text { Total } \\
\text { Holes }\end{array}$ \\
\hline $\begin{array}{l}\text { No of } \\
\text { holes }\end{array}$ & 14 & 04 & 01 & 04 & 04 & 02 & 02 & 02 & 02 & 02 & 02 & 16 & 15 & 04 & $56+4+14$ \\
\hline $\begin{array}{l}\text { Delay } \\
\text { (in ms) }\end{array}$ & 00 & 00 & 25 & 200 & 400 & 600 & 1000 & 1400 & 1800 & 2400 & 3000 & 3800 & 4600 & 5500 & \\
\hline
\end{tabular}

Figure 11 
Existing drilling and blasting pattern practiced at the experimental development face of the mine.

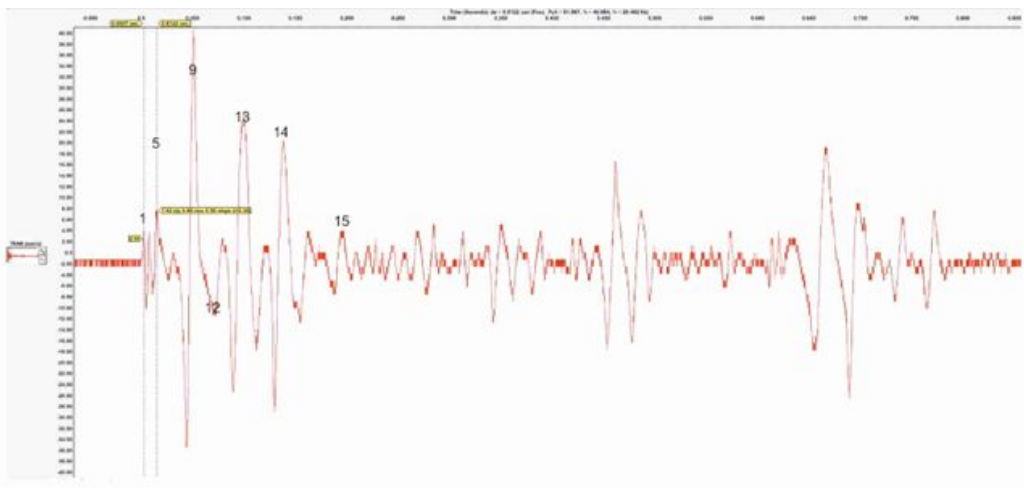

(a) Waveform plot featuring delay timings of the cut holes

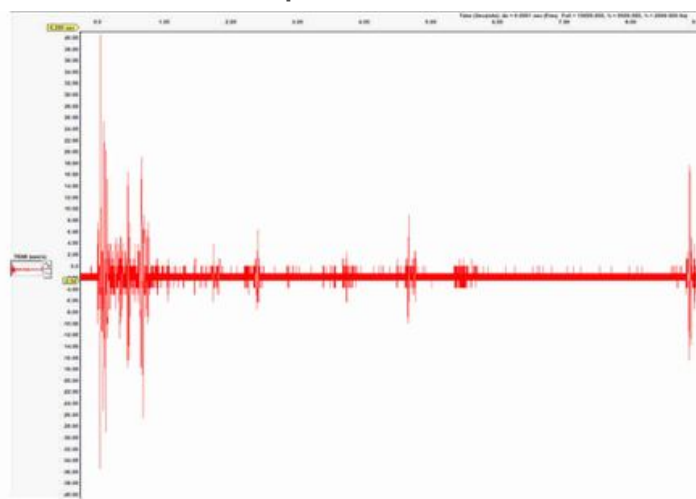

(b) Waveform plot featuring delay timings of all the blast holes

\section{Figure 12}

Recorded waveform for the experimental blast featuring the delay timings of the blast holes.

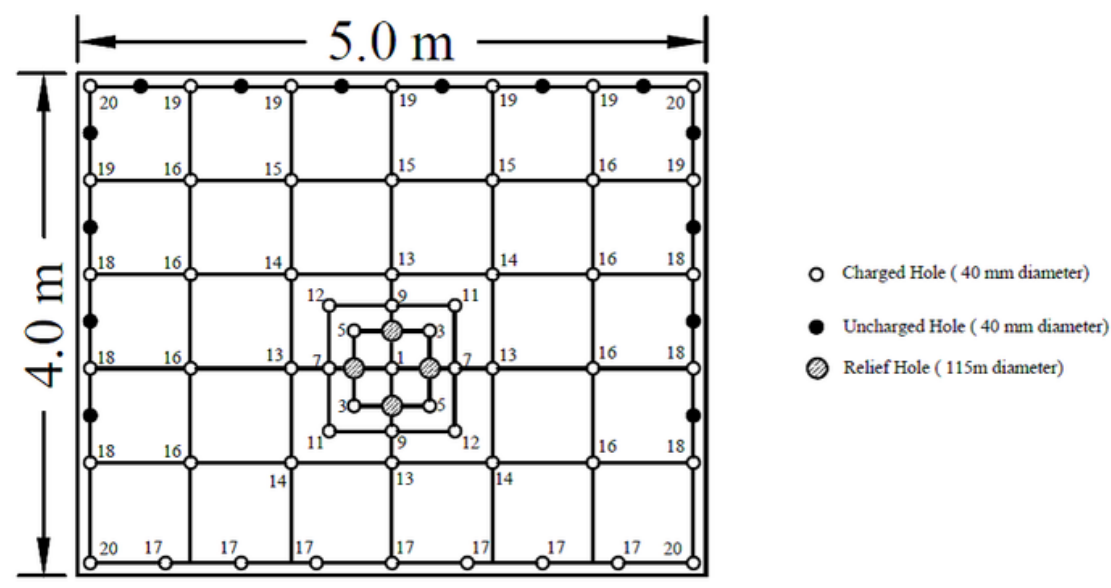

\begin{tabular}{|l|c|c|c|c|c|c|c|c|c|c|c|c|c|c|c|c|c|c|}
\hline $\begin{array}{l}\text { Delay } \\
\text { No }\end{array}$ & $\begin{array}{l}\text { Pre Split } \\
\text { Holes }\end{array}$ & $\begin{array}{l}\text { Relief } \\
\text { Holes }\end{array}$ & 01 & 03 & 05 & 07 & 09 & 11 & 12 & 13 & 14 & 15 & 16 & 17 & 18 & 19 & 20 & $\begin{array}{l}\text { Total } \\
\text { Holes }\end{array}$ \\
\hline $\begin{array}{l}\text { No of } \\
\text { holes }\end{array}$ & 14 & 04 & 01 & 02 & 02 & 02 & 02 & 02 & 02 & 04 & 04 & 03 & 08 & 07 & 06 & 07 & 04 & $56+4+14$ \\
\hline $\begin{array}{l}\text { Delay } \\
\text { (in ms) }\end{array}$ & 00 & 00 & 25 & 100 & 200 & 300 & 400 & 500 & 600 & 1000 & 1400 & 1800 & 2400 & 3000 & 3800 & 4600 & 5500 & \\
\hline
\end{tabular}

\section{Figure 13}

Revised blast design based on the results of the numerical simulation and waveform analysis. 


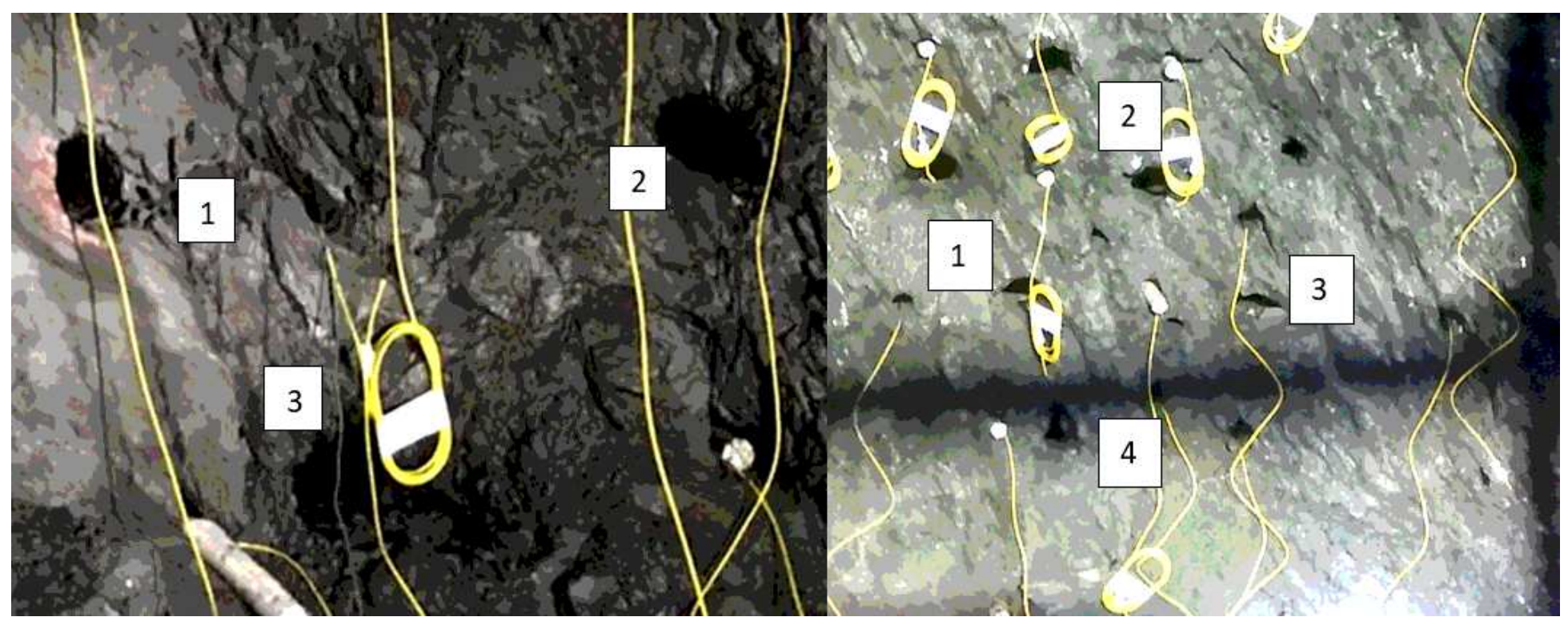

Figure 14

Cut hole pattern with three and four relief holes.

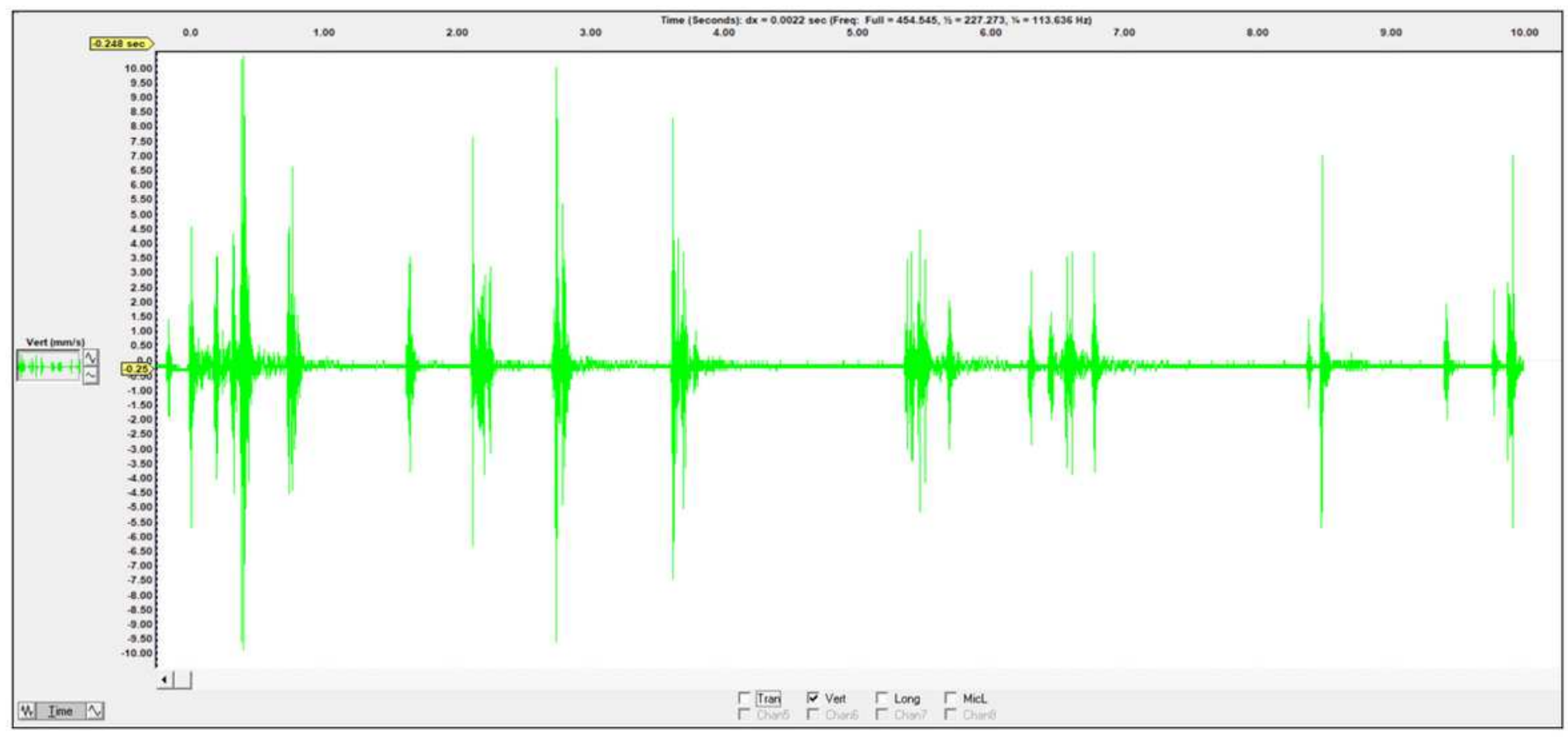

Figure 15

Recorded waveform for the experimental trial with the revised blast design pattern. 